\title{
Measuring Public School Competition from Private Schools: A Gravity-Based Index
}

\author{
Kaustav Misra ${ }^{1}$, Guangqing $\mathbf{C h i}^{2}$ \\ ${ }^{1}$ Department of Economics, Saginaw Valley State University, University Center, USA \\ ${ }^{2}$ Department of Sociology and Social Science Research Center, Mississippi State University, Starkville, USA \\ E-mail: kmisra@svsu.edu,gchi@ssrc.msstate.edu \\ Received April 26, 2011; revised April 25, 2011; accepted May 16, 2011
}

\begin{abstract}
This research develops a gravity-based index of public school competition from private schools within local markets. Proponents of educational reform often call for policies to increase competition between schools. A major hurdle for researchers examining this issue is to determine a workable definition of "competition" by which they can measure the degree of competition within local markets. This study addresses this challenge by developing a school competition index for public schools in the Jackson metropolitan area of Mississippi, USA that considers the enrollments in public schools and the enrollments in their neighboring private schools, as well as the distances between them. The school competition index reveals the degree of competition for each public school based on its spatial location relative to peer private schools operating within its service area. This methodology can be useful for evaluating competition in other markets and redefining the traditional market structure.
\end{abstract}

Keywords: Public School, Gravity-Based Index, Market, Competition, Education

\section{Introduction}

A sense that educational outcomes need improvement is essentially universal, particularly in the United States, where public schools lag behind other countries in standardized student achievement scores [1]. There has been a call for improved educational outcomes, yet such outcomes have been rare because of the inefficiency of public schools [2]. A public school, which is supported by public funds, provides free education for children of a district. Although a major percent of U.S. children go to public schools for their education and funding to public schools has been increased substantially, the performance of public schools has not improved much over time [3]. Between 1996 and 2006, the national average American College Testing (ACT) score has increased negligibly from 20.8 to 21.0 (http://www.act.org/news/data.html). This has come to the attention of parents as well as local and state legislators.

In response to the underperformance of public schools, two types of educational reforms have been proposed by researchers: high-stake tests and market-type reforms [4]. Policy makers propose to increase the achievement levels of standardized test scores in the former, while in the latter reformers propose to increase the number of school choices available to students, primarily by introducing voucher programs and tuition tax credits. The markettype reforms free students from being restricted to attending only public schools in the districts where they reside and thus provide them the option to instead attend private schools of their choice, regardless of their location. In districts where such reforms have been implemented, government-supplied vouchers and tuition tax credit programs have been put in place to offset the costs of private school attendance. Policy reformers believe such promotion of private school attendance generates market-based competition for local public schools.

Some researchers, such as Hoxby [5] and Couch, Shughart and Williams [6], argue that the presence of private schools increases public school qualities; however, other researchers dispute that claim $[7,8]$. It is unclear how private schools affect public schools because it is difficult to measure the degree of competition across educational markets. Previous researchers have employed different proxies to capture the degree of inter-school competition, but these techniques do not reveal all of the relevant information. For example, the most frequently used competition computational techniques include the 
Herfindahl-Hirschman Index [9], the percentage of all students in private schools [10,11], grade-specific competition [12], and market share held by private schools [13]. Each of these techniques is somewhat different from the others. It is important to note that these techniques rely on only the number of schools and student enrollments. These techniques cannot provide accurate estimates for competitiveness, as they ignore the distance between the competitors. Previous literature (e.g., [8,9]) assumes that public school markets are geographically bounded by law and follow the traditional market structure theory [14], where distance between the competitors in the market does not have any place. Hence, a more accurate measure of school competition is to consider not only the number of schools and student enrollments, but also the distance between the competitors.

The primary goal of this manuscript is to propose a measure of school competition by considering not only the number of schools and student enrollments, but also distances between competitors. Specifically, this study develops the school competition index to measure competition for each public school from neighboring private schools in the Jackson metropolitan area, Mississippi, USA. To our best knowledge, this is the first research to accommodate three major components of market competition: the number of competitors, the sizes of the competitors, and the geographical distances among the competitors. Most of the previous research used competition variables by employing either one or two of the three components, but not all three together [8-10,12].

\section{Developing a School Competition Index}

To isolate the school-specific competition effect, we develop a gravity-based school competition index (SCI) that employs three types of market attributes-the number of competitors, the sizes of the competitors, and the geographical distances among the competitors-in a distance-decay function:

$$
A_{i}=\frac{1}{E_{i}} \sum_{i \neq j} E_{j} d_{i j}^{-2}
$$

where $E_{i}$ is the public school's enrollment, $E_{j}$ is its neighboring private schools' enrollments, ${ }^{1}$ and $d$ represents the distances between the public school and each neighboring private school ( $i$ and $j$ denote the public

\footnotetext{
${ }^{1}$ It is legitimate to consider including measures of school qualities such as average GPA, but such data are not publicly available for private schools. Enrollment, then, is the only publicly available choice for proximately representing school qualities. This imposes a limitation to this study. Quality data, for example test scores or student cognitive abilities for private schools should be incorporated into the development of the competition index in future research when such data become available.
}

school and neighboring private schools, respectively).

This gravity-based index considers the number of competitors, the sizes of competitors, and the distances between local competitors. It is important to include the three attributes because each plays a role in affecting competition. First, the number of competitors influences market concentration, and a higher market concentration increases market outcomes more than a lower market concentration [8]. Second, a competitor can compete for market share based on size (a small firm may not be able to compete with a big firm because the small firm will always face resource constraints).

Third, the distance between local competitors is an important factor of competition. According to Tobler's First Law of Geography [15], everything relates to everything else, but the near ones do more than the distant ones. The effect of competition from a closer competitor is higher than the effect from a distant competitor in the same market. Market and human spatial behavior are closely related to each other specifically in the assessment of accessibility and mobility [16]. In the market place, decisions related to the space are often related to distance and time, because increasing travel distance or cost can have an inverse effect on the possible usage [17]. When selecting a potential school, people prefer nearer ones given everything else the same because longer distances mean higher cost and investment. Therefore, travel distance or cost should be included as part of the school choice decision as well.

While developing this index, it is necessary to consider at what distances private schools are competitive to public schools as the law of diminishing returns assume that the degree of competition will start decreasing after an optimal distance [18]. To do this, we refer to the accessibility literature and seek to identify the maximum distance to identify the neighboring private schools of a public school. Garreau [19] argues that 45 minutes is the desirable commuting time regardless of mode of transportation. Dong et al. [20] suggest 27.1 minutes and 31.1 minutes based on activity-based accessibility and trip-based accessibility, respectively. Wheeler [21] finds that the spillover effect of economic growth and activity of a county in the United States starts to decline roughly after 40 miles. In this study, we use 40 miles as the maximum distance at which a private school can compete with a public school. ${ }^{2}$ We define and identify a public school market and measure its competition by drawing a circle with a 40 -mile radius around each public school. All private schools within the circle are considered competitors of that public school.

\footnotetext{
${ }^{2}$ In future research, sensitivity analysis could be conducted by using other distance radiuses.
} 


\section{Data}

In this study, public school annual enrollment data for the academic year 2005-2006 are obtained from the Mississippi Assessment and Accountability Reporting System of the Mississippi Department of Education. We collect private school enrollment data for the academic year 20052006 from the National Center for Education Statistics. The collected data are at the school level. Most previous studies are conducted with enrollment data at the school district, county, or state levels; because the data used in this research are at the school level, this study provides finer estimates of school competition than previous studies.

We consider the public schools located in the Jackson metropolitan area of Mississippi (Figure 1). The primary reason for selecting this area for the research is that the Jackson metropolitan area is the single largest populated area in the state of Mississippi. The number of public and private schools in the Jackson area is significantly higher than the numbers in other areas of Mississippi, and the larger number provides a good number of samples for the analysis. Moreover, the per capita income in the Jackson metropolitan area is much higher than the Mississippi average (Bureau of Economic Analysis, 2005), which allows residents in the Jackson area to afford private schools more than residents outside of the Jackson area. Again, this increases the samples of competitors for the analysis.

The schools considered in this study include both high

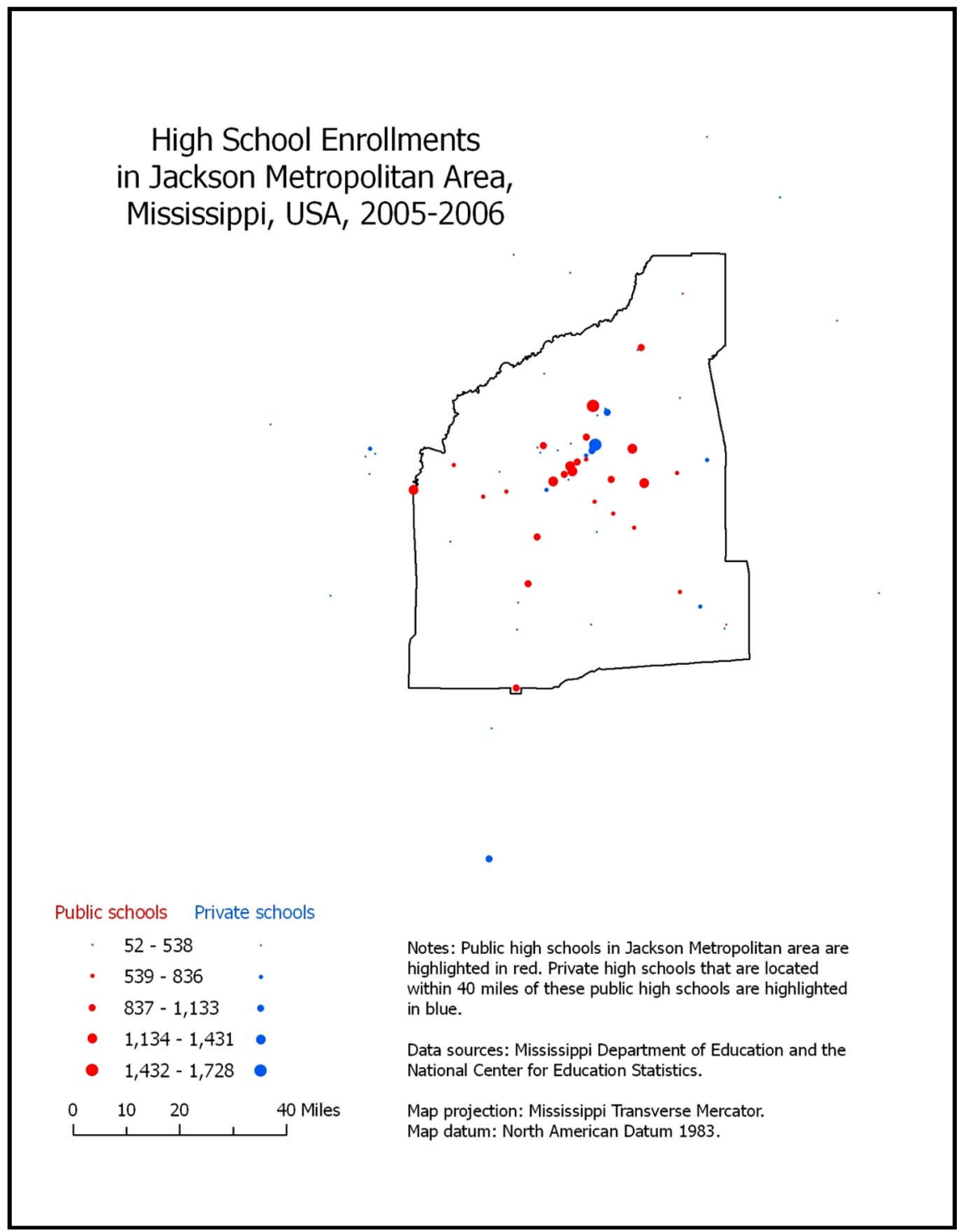

Figure 1. High School Enrollments in the Jackson Metropolitan Area, Mississippi, USA, 2005-2006. 
schools (grades 9 - 12) and combined schools (schools offering grades K-12). In total there are 48 public high schools and combined schools in the Jackson metropoli$\tan$ area. We eliminated 16 schools from the final data set because they typically serve special-education students (schools for the disabled) or special groups of students (schools for juvenile offenders), and such schools do not face competition from the private schools. The final sample data set includes, therefore, 32 public high schools and combined schools as well as the 38 private schools located within 40 miles of these public schools. The locations and enrollments of these schools are shown in Figure 1 and descriptive statistics for public and private schools are shown in Table 1. In terms of enrollment size, public schools are more evenly distributed, but most private schools are small.

\section{Results}

Table 2 provides the descriptive statistics for the generated gravity-based public school competition index. This table reveals how these public schools are distributed in terms of school competition index in the study area. Most of these schools are facing a low degree of competition from private schools.

The school competition index is further illustrated in Figure 2. Smaller red dots represent public high or combined schools with less competition from private schools. Bigger red dots represent public schools with higher competition from private schools. The competition index provides a more accurate estimate of public school competition from private schools than previous studies because it includes three attributes of the market structure-the number of competitors, the sizes of the competitors, and the geographical distances between the competitors.

Two things are notable from Figure 2. One, the enrollment size of a public school is generally negatively correlated with the competition that it faces from local private schools. For example, a high school in the northwest corner of the Jackson metropolitan area has

Table 1. Descriptive statistics of high school enrollments in the Jackson Metropolitan Area, Mississippi, USA, 2005-2006.

\begin{tabular}{ccc}
\hline Enrollment size & Public high schools & Private high schools \\
\hline $52-538$ & $9(28.13 \%)$ & $29(76.32 \%)$ \\
$539-836$ & $8(25.00 \%)$ & $5(13.16 \%)$ \\
$837-1133$ & $8(25.00 \%)$ & $3(7.89 \%)$ \\
$1134-1431$ & $6(18.75 \%)$ & $0(0.00 \%)$ \\
$1432-1728$ & $1(3.12 \%)$ & $1(2.63 \%)$ \\
Total & $32(100 \%)$ & $38(100 \%)$ \\
\hline
\end{tabular}

Table 2. Descriptive statistics of public school competition index (SCI) in the Jackson Metropolitan Area, Mississippi, USA, 2005-2006.

\begin{tabular}{ccc}
\hline SCI range & Frequency & Percentage \\
\hline $0.01-0.05$ & 10 & $31.25 \%$ \\
$0.06-0.09$ & 6 & $18.75 \%$ \\
$0.10-0.18$ & 7 & $21.87 \%$ \\
$0.19-0.66$ & 5 & $15.63 \%$ \\
$0.67-13.70$ & 4 & $12.50 \%$ \\
Total & 32 & $100 \%$ \\
\hline
\end{tabular}

relatively higher enrollment than the other public schools in the area (Figure 1), but this school faces less competition as compared to the other public schools (Figure 2).

In contrast, a school in the southeast corner of the area (Figure 1) has a small enrollment size, but it faces much more competition from private schools (Figure 2). Two, the public schools that are located close to private schools (especially those with high enrollments) face more competition from these private schools. The public schools that are located in the middle of the Jackson metropolitan area have more neighboring private schools; these public schools face higher competition from local private schools.

\section{Conclusions and Discussion}

Proponents of educational reform often call for policies to increase competition between schools. A major hurdle for researchers examining this issue is to determine a workable definition of "competition” by which they can measure the degree of competition within local markets. However, prior measures consider only the number of schools and student enrollments in estimating competition between schools. Distance between potential competitors is also an important factor of competition because travel distance or cost affects school choice decisions.

This research develops a gravity-based index of public school competition from private schools within local markets. We consider three factors - the number of competitors, the sizes of competitors, and the distances between local competitors-in order to comprehensively measure the effect of competition. We demonstrate the use of the method for developing a school competition index for public schools in the Jackson metropolitan area of Mississippi, USA that considers the enrollments in public schools and the enrollments in their neighboring private schools, as well as the distances between them. The school competition index reveals the degree of competition for each public school based on its spatial location relative to peer private schools operating within 


\section{Public School Competition Index in Jackson Metropolitan Areas, Mississippi, USA, 2005-2006}

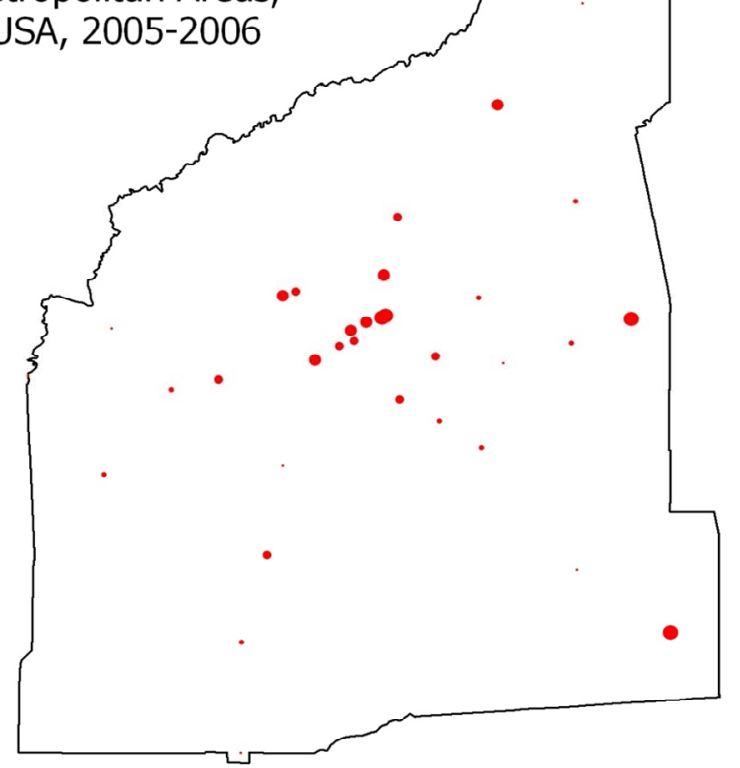

\footnotetext{
$0.01-0.05$

- $0.06-0.09$

- $0.10-0.18$

- $0.19-0.66$

- $0.67-13.70$
}

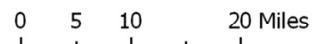

Notes: The public school competition index measures the competition from private schools. The larger red dots represent public schools with higher competition from private schools. The smaller red dots represent public schools with lower competition from private schools.

Data sources: Mississippi Department of Education and the National Center for Education Statistics.

Map projection: Mississippi Transverse Mercator. Map datum: North American Datum 1983.

Figure 2. Public school competition index in the Jackson Metropolitan Area, Mississippi, USA, 2005-2006.

its service area. This methodology can be useful for evaluating competition in other markets and redefining the traditional market structure.

This study makes two contributions to the literature on market structure and competition. First, this study adds distance into the measure of school competition. The distance between competitors is often ignored in the traditional market structure theory, but spatial proximity plays an important role in the human decision-making process [22]. Thus, it is important to consider distance when determining market competition. Second, the gravity-based competition index can be used to evaluate competition-based educational reform programs. Prior competition measures may not be effective instruments for understanding school market strength since the distance component is missing from the measures. This leads to inappropriate policy recommendations and misallocation of scarce resources because focusing on only one component at a time without considering them together may underestimate the true effect of competition. Because this gravity-based index includes the three attributes of competition-the number of competitors, the sizes of the competitors, and the geographical distances among the competitors-it provides a more accurate estimate of competition and thus helps guide state and local public education agencies in allocating their resources more effectively.

\section{References}

[1] S. Baldi, Y. Jin, M. Skemer, P. J. Green and D. Herget, "Performance of U.S. 15-Year-Old Students in Science and Mathematics Literacy in an International Context," National Center for Education Statistics, U.S. Department of Education, Washington, DC., 2007. 
[2] E. A. Hanushek and L. Woessmann, "Do Better Schools Lead to More Growth? Cognitive Skills, Economic Outcomes, and Causation,” Working Paper 14633, National Bureau of Economic Research, Cambridge, 2009.

[3] J. R. Betts, "Returns to Quality of Education,” Economics of Education Series 1, Economics of Education Thematic Group, The World Bank, Washington, DC., 1999.

[4] C. R. Belfield and H. M. Levin, "The Effcets of Competition Between Schools on Educational Outcomes: A Review for the United States," Review of Educational Research, Vol.72, No. 2, 2002, pp. 279-341. doi:10.3102/00346543072002279

[5] C. M. Hoxby, "Do Private Schools Provide Competition for Public Schools?” NBER Working Paper Series, National Bureau of Economic Research, Cambridge, 1994.

[6] J. F. Couch, W. F. Shughart and A. Williams, "Private School Enrollment and Public School Performance," Public Choice,Vol. 76, No. 4, 1993, pp. 301-312. doi:10.1007/BF01053301

[7] C. M. Newmark, "Another Look at Whether Private Schools Influence Public School Quality: Comment," Public Choice, Vol. 82, No. 3-4, 1995, pp. 365-73. doi:10.1007/BF01047704

[8] W. Sander, "Private Schools and Public School Achievement," Journal of Human Resources, Vol. 34, No. 4, 1999. pp. 697-709. doi:10.2307/146413

[9] M. V. Borland and R. M. Howsen. "Students' Academic Achievement and the Degree of Market Concentration in Education," Economics of Education Review, Vol. 11, No. 1, 1992, pp. 31-39. doi:10.1016/0272-7757(92)90019-Y

[10] C. Jepsen, "The Role of Aggregation in Estimating the Effects of Private School Competition on Student Achievement,” Journal of Urban Economics, Vol. 52, No. 3, 2002, pp. 477-500. doi:10.1016/S0094-1190(02)00530-2

[11] R. Mcmillan, "Competition, Parental Involvment, and Public School Performmance,” National Tax Association,
Washington, DC., 2001, pp. 150-155.

[12] C. R. Geller, D. L. Sjoquist and M. B. Walker, "The Effect of Private School Competition on Public School Performance in Georgia,” Public Finance Review, Vol. 34, No. 1, 2006, pp. 4-32. doi:10.1177/1091142105283631

[13] R. Arum, "Do Private Schools Force Public Schools to Compete?” American Sociological Review, Vol. 61, No. 1, 1996, pp. 29-46. doi:10.2307/2096405

[14] R. G. Hubbard and A. P. O’Brien, "Principles of MicroEconomics," 2nd Edition, Prentice Hall, Boston, 2008.

[15] W. Tobler, "A Computer Movie Simulating Urban Growth in the Detroit Region," Economic Geography, Vol. 46, 1970, pp. 234-240. doi:10.2307/143141

[16] A.S. Fortheringham. Spatial Structure and Distancedecay Parameters. Annals of the Association of American Geographers. Vol. 71, No. 3, 1981, pp. 425-436.

[17] J. G. Koenig, "Indicators of Urban Accessibility: Theory and Application," Transportation, Vol. 9, 1980, pp. 145-172. doi:10.1007/BF00167128

[18] R. W. Shephard, "Proof of the Law of Diminishing Returns," Zeitschrift fur Nationalokonomie, Vol. 30, 1970, pp. 7-34. doi:10.1007/BF01289990

[19] J. Garreau, “Edge City: Life on the New Frontier,” Doubleday, New York, 1991.

[20] X. Dong, M. E. Ben-Akiva, J, L. Bowman and J. L. Walker, "Moving from Trip-Based to Activity-Based Measures of Accessibility," Transportation Research Part A, Vol. 40, No. 2, 2006, pp. 163-180. doi:10.1016/j.tra.2005.05.002

[21] C. Wheeler, "A Note on the Spatial Correlation Structure of County-Level Growth in the US,” Journal of Regional Science, Vol. 41, No. 3, 2001, pp. 433-449. doi:10.1111/0022-4146.00225

[22] J. H. Knorring. "Basic Human Decision Making: An Analysis of Route Choice Decisions by Long-Haul Truckers,” Ph.D. Dissertation, Princeton University, Princeton, 2003. 